\title{
RESENHA
}

\section{POLÍTICAS PÚBLICAS: compreendendo referenciais teóricos, conceito e análises}

\author{
Daniela dos Santos Caetanol \\ Ingred Luana Souza Rosário Tanihara² \\ Sandra Fernandes Leite 3
}

SECCHI, Leonardo. Políticas Públicas: conceitos, esquemas de análise, casos práticos. 2.ed. São Paulo: Cengage Learning, 2013. ISBN 978-85-221

O livro "Políticas Públicas: conceitos, esquemas de análise, casos práticos", lançado em 2010 e relançado posteriormente com uma $2^{a}$ edição em 2013, corresponde a um manual didático voltado para estudiosos e interessados em compreender os referenciais teóricos, conceituais e analíticos da área das políticas públicas. O livro está estruturado em seis capítulos dos quais são abordadas cinco dimensões elementares: a dimensão de conteúdo no capítulo 2, a dimensão temporal no capítulo 3 , a dimensão espacial no capítulo 4, a dimensão de atores no capítulo 5 e a dimensão comportamental no capítulo 6.

O autor lança mão de uma linguagem simples e fluída que possibilita ao leitor conhecer princípios elementares da área, além de tornar possível o aprofundamento do conteúdo exposto por meio dos minicasos, exercícios de fixação, questões de múltipla escolha e referências bibliográficas apresentadas ao final de cada capítulo.

\footnotetext{
1 Mestranda em Educação. Programa de Pós-Graduação em Educação da Faculdade de Educação da Unicamp. Campinas/SP. E-mail: danieladossantoscaetano@gmail.com

2 Mestranda em Educação. Programa de Pós-Graduação em Educação da Faculdade de Educação da Unicamp. Campinas/SP. E-mail: ingredrosario@gmail.com

3 Doutora em Educação (UNICAMP). Professora do Programa de Pós-Graduação em Educação da Faculdade de Educação da Unicamp. Campinas/SP. E-mail: sfleite@unicamp.br
} 
No capítulo I," Introdução: Percebendo as Políticas Públicas", o autor aponta e diferencia os sentidos relacionados a definição da palavra política (politcs e policy, a primeira apresentada como área de conhecimento e/ou ciência relativa ao exercício do poder e a segunda como norma, conduta, ou a política em preparação e execução) e evidencia os contornos do que significa a política pública sob a perspectiva da policy, ou seja, enquanto "[...] diretriz elaborada para enfrentar um problema público[...]" (SECCHI, 2013, p. 2).

Destaca-se no decorrer do capítulo a discussão acerca de uma definição para política pública em referência às suas abordagens (estadista ou estadocêntrica e/ou multicêntrica ou policêntrica) à essência do que significa uma política pública em relação a um problema público e o posicionamento adotado "[...] as políticas públicas são tanto as diretrizes estruturantes (de nível estratégico) como as diretrizes de nível intermediário e operacional [...]" (SECCHI, 2013, p.7) e exemplos de políticas públicas em diversas áreas, tais como na saúde, educação, segurança entre outras.

No capítulo II, "Tipos de Política Pública", o autor retoma o conceito de politics e policies 4 para discorrer sobre o modo como a ciência tradicional tratava da policies enquanto variáveis dependentes das politics, todavia, através dos estudos de Theodore J. Lowi (1972 apud SECCHI, 2013) e da máxima de que "[...] as políticas públicas determinam a dinâmica política" (SECCHI, 2013, p. 23), compreendeu-se que os determinantes dos tipos de políticas públicas influenciam também o desempenho da política (politics) e que ambas podem se influenciar mutuamente.

Outrossim, em relação a tipologia de políticas públicas, o autor apresenta as tipologias de Lowi (1972 apud SECCHI, 2013), Wilson (1983 apud SECCHI, 2013), Gormley (1986 apud SECCHI, 2013), Gustafsson (1983 apud SECCHI, 2013) e Bozeman e Pandey (2004 apud SECCHI, 2013), além de elaborar sobre a criação das tipologias e as limitações desta forma de análise.

\footnotetext{
${ }_{4}^{4}$ Plural de policy.
} 
A tipificação representa um elemento essencial para o conhecimento e a organização de determinada política pública e, embora não apresente profundidade, torna-se essencial para promover o conhecimento acerca das categorias e variáveis das ações política/governamentais que circundam a área.

No capítulo III, "Ciclo de Políticas Públicas", põe-se em relevo a elaboração das políticas públicas, ou seja, o ciclo de políticas no que concerne a "[...] um esquema de visualização e interpretação que organiza a vida de uma política pública5 em fases sequenciais e interdependentes [...]" (SECCHI, 2013, p. 43). O modelo exposto apresenta sete fases cruciais: identificação do problema; formação de agenda; formulação de alternativas; tomada de decisão; implementação; avaliação e extinção.

O interesse dos atores políticos após a identificação de determinado problema público e o interesse em sua resolução pode vir a se tornar uma de suas prioridades, o que significa um item para a agenda. A agenda corresponde a uma lista de problemas e assuntos que despertaram interesses e que são passíveis de resolução por parte de um ou diversos atores políticos. O autor pontua três tipos de agenda: a agenda política, a agenda formal e a agenda da mídia.

No que tange à formulação de alternativas, ela corresponde à formulação de objetivos, estratégias e estudos das consequências a fim de propor alternativas possíveis para a resolução do problema. Segundo o autor, "A etapa de construção de alternativas é o momento em que são elaborados métodos, programas, estratégias ou ações que poderão alcançar os objetivos estabelecidos [...]" (SECCHI, 2013, p. 48).

A tomada de decisão se traduz no equilíbrio dos interesses dos atores políticos, bem como no desvelamento do plano de ação. Apresenta-se uma síntese dos modelos de tomada de decisão: racionalidade absoluta, racionalidade limitada, modelo incremental e modelo da lata de lixo/fluxos múltiplos.

\footnotetext{
${ }^{5}$ Grifo do autor.
} 
No que condiz com a implementação da política pública, representa o processo de se converter o planejamento idealizado em ação e a importância de seu estudo compreende tanto a possibilidade de visualizar obstáculos e falhas atuais quanto erros anteriores (SECCHI, 2013).

A fase posterior diz respeito à avaliação da política pública, momento de exame das fases posteriores a fim de produzir um retorno ou uma resposta à ação. O autor apresenta com critérios para as avaliações: economicidade; eficiência econômica; eficiência administrativa; eficácia; equidade. Outra importância se refere aos parâmetros e rumos que determinada política pública pode levar.

Por fim, na fase da extinção da política pública, o autor menciona que os estudos relativos a este tema tiveram início na década de 70 com o questionamento sobre determinadas "[...] políticas sociais vinculadas ao Estado de bem-estar social [...]" (SECCHI, 2013, p.67). A extinção condiz com três elementos: a resolução do problema público; a ineficácia dos programas ou projetos; o problema deixou de constituir a agenda. Da mesma forma, o jogo político, as alternâncias de poder e discursos também corroboram para a extinção de determinadas políticas públicas.

No capítulo IV, "Instituições no Processo da Política", as atenções estão voltadas para a dimensão espacial, ou seja, o lugar, o contexto em que as políticas acontecem. O autor enfatiza que a atividade política se diferencia em relação a um ou outro espaço e que esta dimensão na área das políticas públicas também é conhecida por ser desenvolver num cenário político/ institucional.

Pontua-se as definições para o termo instituição, como entidades/ organizações, princípios moderadores/normas ou pelo viés da política pública, como normas, regras, códigos entre outros voltados para arenas onde se concebem tais políticas (...). Instituições nessa acepção são: jurisdições (leis), competências (funções) e as delimitações territoriais" (SECCHI, 2013, p. 82). 
Explicita-se também que foi na década de 80 que o novo institucionalismo, ou neoinstitucionalismo, ganhou destaque, influenciando e atuando diretamente nos comportamentos sociais dos sujeitos.

O autor apresenta o conceito de cultura política para salientar três tipos: cultura paroquial, cultura submissa e cultura participativa. No que tange à análise das pluralidades, particularidades e das diferenciações das culturas políticas no âmbito institucional, expõe-se a possibilidade da criação de tipologias "[...] são necessários estudos e tipologias que sublinhem as diferenças de contextos institucionais, infranacionais, infrarregionais e intraorganizacionais, na tentativa de capturar as nuanças das regras localizadas e das microculturas" (SECCHI, 2013, p. 89).

O autor inicia o capítulo V, "Atores no Processo de Política Pública", recuperando a noção de que atores são os sujeitos, grupos, organizações que compõem as arenas e nelas desenvolvem determinada função. "[...] Os atores relevantes em um processo de política pública'são aqueles que têm capacidade de influenciar, direta ou indiretamente, o conteúdo e os resultados da política pública [...]" (SECCHI, 2013, p. 99).

Externa-se a possibilidade de se analisar os atores por meio de uma tipificação, recorrendo a categorias que agrupem as características comuns e discrimine as características diferentes, assim como identificar e dividir entre atores individuais e atores coletivos.

Salienta-se outros atores já identificados e caracterizados, fundamentais à compreensão da dinâmica política. De cunho governamental são os políticos, designados politicamente, burocratas e juízes. De cunho não-governamental se encontra os grupos de interesse, partidos políticos, meios de comunicação, think thanks, destinatários das políticas públicas, organizações do terceiro setor e outros stakeholders (fornecedores, organismos internacionais, comunidades epistêmicas, financiadores, especialistas entre outros).

${ }^{6}$ Grifo do autor. 
No que se refere aos modelos desenvolvidos pelos atores reconhecidos como stakeholders, constatam-se: o modelo principal-agente; redes de políticas públicas, modelos elitistas, modelo pluralista; triângulo de ferro.

O capítulo VI, "Estilos de Políticas Públicas", aborda o modo pelo qual se conduz determinada política, a metodologia adotada pelos decisores políticos e a importância da análise de estilos de políticas públicas "[...] tanto para fins descritivos (de que maneira funcionam as coisas) como para fins prescritivos (de que maneira deveriam funcionar as coisas)" (SECCHI, 2013, p. 136).

Indica-se a "Tipologia de Richardson, Gustafsson e Jordan" porque se trata da distinção de estilos de políticas públicas (SECCHI, 2013). Tal tipologia aponta duas variáveis relativas à abordagem na resolução de problemas (de proativo a reativo) e à relação entre atores governamentais e atores sociais (consensual a impositivo) (SECCHI, 2013, p. 136).

Na estrutura de resolução de problemas, o que se chama de proativo corresponde à racionalidade, já o que se configura como reativo condiz com o incrementalismo. O eixo consensual-impositivo trata das tomadas de decisões dominantes ou mais arbitrárias em face de tomadas de tomadas de decisões mais flexíveis, abertas a maior participação de outros atores. $O$ autor também demarca a oposição do estilo regulatório para o estilo gerencial e denota a relevância da participação na construção de políticas, analisando a distinção entre decisão coletiva e deliberação.

Recebida em: 16 de novembro de 2017

Aprovada em: 15 de fevereiro de 2018 